\title{
A longitudinal analysis of the choice between technology-based strategic alliances and acquisitions in high-tech industries : the case of the ASIC industry
}

Citation for published version (APA):

Vanhaverbeke, W. P. M., \& Duysters, G. (1997). A longitudinal analysis of the choice between technologybased strategic alliances and acquisitions in high-tech industries : the case of the ASIC industry. NIBOR, Netherlands Institute of Business Organization and Strategy Research. NIBOR Research Memorandum No. 007 https://doi.org/10.26481/umanib.1997007

Document status and date:

Published: 01/01/1997

DOI:

10.26481/umanib.1997007

Document Version:

Publisher's PDF, also known as Version of record

Please check the document version of this publication:

- A submitted manuscript is the version of the article upon submission and before peer-review. There can be important differences between the submitted version and the official published version of record.

People interested in the research are advised to contact the author for the final version of the publication, or visit the DOI to the publisher's website.

- The final author version and the galley proof are versions of the publication after peer review.

- The final published version features the final layout of the paper including the volume, issue and page numbers.

Link to publication

\footnotetext{
General rights rights.

- You may freely distribute the URL identifying the publication in the public portal. please follow below link for the End User Agreement:

www.umlib.nl/taverne-license

Take down policy

If you believe that this document breaches copyright please contact us at:

repository@maastrichtuniversity.nl

providing details and we will investigate your claim.
}

Copyright and moral rights for the publications made accessible in the public portal are retained by the authors and/or other copyright owners and it is a condition of accessing publications that users recognise and abide by the legal requirements associated with these

- Users may download and print one copy of any publication from the public portal for the purpose of private study or research.

- You may not further distribute the material or use it for any profit-making activity or commercial gain

If the publication is distributed under the terms of Article 25fa of the Dutch Copyright Act, indicated by the "Taverne" license above, 
A longitudinal analysis of the choice between technology-based strategic alliances and acquisitions in hightech industries: The case of the ASIC industry

W. Vanhaverbeke \& G. Duysters

$\mathrm{NIBOR} / \mathrm{RM} / 97 / 07$

http://www.unimaas.nl/ document/fdewb.htm

J.E.Lit. code: $\mathrm{O} 32$

$n i b \circ r$

Netherlands Institute of

Business Organization

and Strategy Research

University of Maastricht

Faculty of Economics and Business Administration

P.O. Box 616

6200 MD Maastricht

The Netherlands

Phone: ++31 43 - 3883805 


\title{
A longitudinal analysis of the choice between technology-based strategic alliances and acquisitions in high-tech industries : The case of the ASIC industry
}

\author{
Wim Vanhaverbeke and Geert Duysters* \\ February 1997
}

\begin{abstract}
Firms producing application specific integrated circuits (ASICs) have established numerous technology based strategic alliances (SAs) and were involved in merger and acquisition activities (M\&As) to enhance their competitive position by improving their learning capabilities and the timely access to technological knowledge that is otherwise unavailable. There exist broad economic and managerial strands of literature about SAs and M\&As, but they tell us virtually nothing about the strategic choice of firms between technology based SAs and M\&As. This article intends to fill this void. It examines the circumstances in which ASIC-producers choose for SAs or M\&As and it analyses how prior SAs influence this choice. Finally, implications for innovation management in high-tech industries are examined.
\end{abstract}

Wim Vanhaverbeke

Maastricht University

NIBOR

P.O. Box 616

6200 MD Maastricht

The Netherlands

Tel:

Fax:

E-mail:
Geert Duysters

Maastricht University

Dept. of International Business Studies

P.O. Box 616

6200 MD Maastricht

The Netherlands

$0031433883805 \quad 0031433883699$

0031433258495

w.vanhaverbeke@mw.unimaas.nl

g.duysters@mw.unimaas.nl

${ }^{*}$ We thank Arjen van Witteloostuijn for his helpful comments. 


\section{Introduction}

Many high-tech industries are characterised by fierce competition. At the same time, cooperation and external technology acquisition is essential to the survival and growth of companies in these industries. The creation of new technological capabilities through endogenous $R \& D$ efforts is crucial to create sustainable performance differentials with other firms (Leonard Barton (1994)). But although these internal resources are important, efficient learning from external resources might be as crucial to successful innovations (Cohen and Levinthal (1989)). Accelerating R\&D efforts and the development of internal innovative capabilities are no longer sufficient to cope with the increasing cost, speed and complexity of technological developments in high-tech industries. Even the largest companies are obliged to use external sources of technology through licensing, strategic technology agreements or mergers and acquisitions (see Gomes-Casseres, (1996); Mytelka, (1991); Teece, 1992)).

In this article we explore the choice of innovating firms between two alternative modes of external sourcing of technology; i.e. cooperation by means of strategic technology alliances on the one hand and merger or acquisition activities on the other hand. Strategic technological alliances (SAs) or mergers and acquisitions (M\&As) are increasingly necessary to develop and renew technological capabilities of firms in high-tech industries. There exist broad economic and managerial strands of literature about SAs and M\&As ${ }^{1}$, but they tell us virtually nothing about the strategic choice of firms between technology based SAs and M\&As. ${ }^{2}$

This study article intends to fill this void. It examines the circumstances in which producers of application-specific integrated circuits (ASICs) choose for SAs or M\&As, and it analyses how prior SAs influence this choice. The central questions in this study are: with whom do firms establish SAs, and with whom do they get involved in M\&A activities? To formulate an answer to these questions one has to shift

For strategic alliances, see Barley et al. (1992); Contractor and Lorange (1988); Hamel (1991); Harrigan (1985); Harrigan and Newman (1990); Kogut (1988a); Porter and Fuller (1986); Powell and Brantley (1992). For M\&As, see Hitt et al. (1991) Mueller (1989); Perry and Porter (1985)

Notable exceptions are Hagedoorn and Sadowski (1996) and Hagedoorn and Duysters (1996). 
away from the firm toward the dyad as the unit of analysis. This study examines the factors explaining why some of the external technology sourcing during the observed time period is realised by means of a SA and not by a M\&A activity.

Choosing between SAs and M\&As may depend on at least four factors. First, it will be argued that SAs are relatively more used when the external technology source is located abroad (inter-triad), while M\&As are widely used for domestic or intra-triad sourcing of technology. Similarly, it matters whether external sourcing of technology takes place within the industry boundaries or across industries. Second, prior alliances play a role in shaping the current choice between SAs and M\&As. Prior alliances - both direct and indirect - create a social network which becomes an important source of information about new alliance or takeover opportunities. Third, the choice between SAs and M\&As may also be influenced by firm effects. A firm with successful experiences with one of these modes of external technology sourcing can expose routine behaviour. Large firms may behave differently than small ones, and captive producers of ASICs can choose differently than open market vendors. Finally, the choice between SAs and M\&As also depends on industry conditions : different phases in the business life cycle are likely to be associated with different preferences for SAs and M\&As. As both modes of external technology sourcing comes in waves, the possible influence of mimetic behaviour on alliance formation and M\&A-activities should be taken into consideration.

The paper is organized as follows. In the next section the ASIC industry is briefly described. In the third section, we scan the literature concerning alternative governance modes with rspect to external technology sourcing and we formulate several hypotheses. The fourth section describes the statistical method and the different variables. Next, we focus on the results in the fifth section. Finally, conclusions are drawn and suggestions for future research are made in a final section.

\section{The ASIC industry}

\section{1}

Definition and characteristics

ASICs - i.e., application specific integrated circuits - are a special type of ICs (integrated circuits) accounting for about $16 \%$ of the worldwide IC market sales in 1994. The term ASIC, 
as now known in the IC industry, is a misnomer. In reality, they are customer specific ICs (CISCs) because an ASIC is a device made specifically for one customer; a device which is made for one particular type of system function (e.g., disk-drives, CD-players, video compressing) but is sold to more than one customer, is considered as an ASSP (application specific standard product). ${ }^{3}$ Although ASSPs are manufactured using ASIC technology, they are ultimately sold as standard devices to numerous users.

The ASIC market is a typical high-tech industry; technology is the driving force shaping the competition among firms and $R \& D$ to sales ratios are exceptionally high. The ASIC market can be divided into different submarkets. According to the "Integrated Circuit Engineering Corporation" (ICE) the ASIC-market includes the following categories of ICs: arrays, custom ICs, and the programmable logic devices (PLDs). Formal definitions are given in table 1 and diagrammed in figure 1.

\section{Insert table 1 about here}

\section{Insert figure 1 about here}

A wide range of specific system functions can be fabricated alternatively by gate arrays, full custom devices or PLDs. These three ASIC-categories are different devices realising the same system functionalities. As a result, there is almost no affinity between the targeted system function and the type of ASIC to use. The only exception is linear arrays, which are used to design analog or mixed (analog/digital) system functions. Linear arrays are applied mainly in the telecommunication and consumer electronics markets, where most signals are analog in nature.

ASIC vendors typically have to make a choice between the three ASIC types minimizing the volume-dependent total cost per chip. PLDs are the cheapest solution for low volume ASICs. Once the production volume exceeds the level of a few thousands units, gate arrays become the most interesting ASIC solution.Custom ICs are the most efficient solution for production volumes that exceed several hundred-thousands of ASICs.

\footnotetext{
3 Sometimes, ASSPs are also called ASIPs (Application Specific Integrated Processors).
} 


\section{acquisition strategies}

The development and production processes of ASICs requires the interplay between different economic agents. The most important participants are the ASIC design houses, IC manufacturing facilities, electronic system houses and CAD-tool vendors. The list can be enlarged by a number of auxiliary and/or intermediate players, such as companies offering services in the microelectronics field, firms that translate customers' needs into the specifications for the design of ASICs and university labs. The interplay between different agents is shown in figure 2.

\section{Insert figure 2 about here}

The best way to explain the interplay between participants is to describe the different development and production stages of ASICs.

The development and production of ASICs requires an intensive interaction and communication between the different players. As internal communication is easier than external communication, there may be some scope for vertical integration between system manufacturers, design houses, CAD-vendors and ASIC-producers. However, the succesful development and production of ASIC demand many different competencies such as, writing specs, design, signoff, processing, CAD-tool development and updating process technology - which may be too costly to develop within the boundaries of a single firm. As a result, the ASIC market is characterised by a mix of newcomers, mergers and acquisitions and strategic alliances.

Electronic system manufacturers usually build a foothold in the ASIC market by vertical integration: they want to achieve or sustain a competitive advantage for their electronic systems through proprietary ASIC designs. Electronic system manufacturers also make corporate-wide deals and second-source agreements with foundries. Large system manufacturers have their own ASIC design house and foundry or they acquire one. Vertically integrated system manufacturers still cooperate with specialised design houses because of recurrent peaks in design work. Large, integrated electronic system manufacturers have their own fab-lines. 
Their ASICs are processed together with standard ICs. ${ }^{4}$ Smaller companies set up agreements with different foundries to process their ASICs. Second-source agreements are frequently used in order to ensure availability of ASICs on time and to avoid lock-in situations. Captive producers - e.g., IBM and DEC - also establish second-source agreements because of peaks in demand. As ASIC-designs become increasingly complex, companies establish numerous joint development and cross-licensing agreements. Some ASIC vendors are also active in the CADtool market - e.g., VLSI Technology. The CAD-tool market is small, and tool development is very expensive. Installing the same CAD-infrastructure among interacting firms greatly enhances technology transfer. Therefore, numerous strategic alliances are established between ASIC producers and CAD-tool vendors. The CAD-tool market is furthermore characterised by an ongoing process of acquisitions by the largest CAD-tool vendors and entries by de novo firms and spin-offs.

In short, most strategic alliances and M\&A-activities in the ASIC-industry seem to be strategic tools for external technology sourcing or acquisition. In a turbulent high-tech environment as the ASIC-industry, firms are likely to link up with each other in order to keep up with the newest technologies. Stand-alone strategies might no longer be viable, even for the largest companies.

\section{Theory and hypotheses}

In order to explain the choice between SAs and M\&As, firms or dyads of allied firms can be adapted as the unit of analysis. The scope of both types of analysis differs significantly. An analysis on the firm level links the relative preference of a company for SAs vis-à-vis M\&As to different firm and industry characteristics, focusing on why and when firms enter alliances and M\&A-activities. An analysis on the dyad level also takes into account characteristics of the external relationship itself (next to firm and industry effects), linking the occurrence of SAs and M\&As to differences or similarities between the firms involved. In this way, the analysis on the dyad level focuses on 'who is linked with whom by what type of inter-firm agreement?'

As a result, hypotheses will be split up in three major categories, the first relates to the

4 Processing ASICs together with standard ICs creates a considerable cost advantage, but is also characterised by disadvantages vis-à-vis specialized ASIC-foundries in terms of flexibility and the minimum efficient scale of production runs. 
specific characteristics of the external relationship (or dyad), the second focuses on firmspecific characteristics and the third on industry features.

\subsection{Domestic versus international external relationships}

The choice between SAs and M\&As will most likely be different for domestic (intra-triad) and international (inter-triad) external relationships. From a transaction cost perspective, the increase in the level of uncertainty associated with international contacts is expected to be offset by an increased need of control. In other words; the incidence of M\&As in international compared to domestic external domains. Kay (1991), on the contrary, argues that relatively more M\&As will be used, the higher the degree of market completion. He found empirical support for this argument. In table 2 the aversion ratio (the number of mergers divided by the number of joint ventures) of community-based companies is shown for different degrees of market completion.

\section{Insert table 2 about here}

Kay (1991) presents two arguments to explain this phenomenon. First, the more open the market, the more likely it is that firms can compete on their own. Hence, the need to establish SAs is smaller as intra-triad geographical expansion strategies can be realized by means of greenfield strategies and M\&A-activities. Second, potential collaborators are also potential competitors in domestic markets, an argument even more important within the context of a high-tech industry as the ASIC industry. An innovating firm can loose valuable technological know-how through learning of the ally within the SA, leading to considerable market share losses. Allies in international SAs experience a stronger strategic interdependence; i.e., an organization has resources or capabilities beneficial to but not possessed by the other (Aiken and Hage (1968)), which in turn results in the formation of SAs.

Hypothesis 1: $\quad$ External sourcing of technology will take the form of $M \& A s$ in the case of intra-triad external relations, and SAs in the case of intertriad external relations

\subsection{External relationships within and between industries}

ASIC-producers established SAs and were involved in M\&A activities with other firms belong- 
ing to the same or another submarket of the ASIC industry (gate arrays, (semi-)custom ICs, and PLDs) or with CAD-tool vendors and electronic system manufacturers. Several authors stress the importance of similarity or complementarity of products or technologies in the decision whether the external sourcing of technology should take the form of an SA or a M\&A. High-tech firms have to renew and deepen their internal technological capabilities in order to develop new products. A few authors (Roberts and Berry (1985); Gomes-Casseres (1996)) argue that firms have the propensity to acquire the other company has similar technological competencies, i.e. when it is part of the same industry. When the partener has complementary or completely new technologies to offer, then SAs are considered to be the best way to cooperate.

An ASIC-producer usually has already developed innovative capabilities or core competences in the submarket(s) in which it is active. To protect these technological capabilities, the firm will prefer M\&As over SAs if it sources technology from another ASIC-producer in the same submarket. When an ASIC-producer intends to develop new products outside its existing product domain, it needs to establish new technological capabilities. In this case, strategic interdependence is larger, implying that SAs will be preferred over M\&As. Similarly, Chi (1994) and Teece (1986) argue that firms will be involved in M\&A-activities when bothe firms have similar innovating capabilities. SAs will be preferred in the case that the partnering firms have different or complementary technological capabilities.

Hypothesis 2: $\quad M \&$ As are positively associated with outside-industry linkages, and negatively with inside industry partnering. The opposite holds true for SAs.

\section{3.}

The influence of prior SAs

The choice between SAs and M\&As is likely to be influenced by the prior experience of firms with SAs. ${ }^{5}$ Basically, the network of prior SAs basically has two effects on firms' behaviour. On the one hand, it serves as a basis for trust between partners, so that prior alliances enhance the possibility of further ties between these firms. On the other hand, information about the partner's capabilities obtained by prior SAs makes firms vulnerable to partners' opportunistic

5 The influence of prior acquisitions cannot be examined here due to lack of data. 
behaviour, so that prior SAs are likely to increase the possibility of acquisition activities.

\subsection{1 $\quad$ Routines of partnering and acquisition strategies}

A widely observed phenomenon is that firms repeat specific previous actions. Organizational routines and inertia are key characteristics of many - if not all - organizations (Cyert and March (1963); Nelson and Winter (1982); Hannan and Freeman (1984); Amburgey et al. (1993)). In this literature the argument is that companies develop routines and competencies over time which then become independent drivers of further actions. Hence, actions in the past are likely to be repeated in the future. This line of reasoning has been applied in the literature on SAs and M\&As too. Amburgey and Miner (1992) argue that firms engaging in an acquisition develop competencies in the process of acquiring other firms. Each acquisition allows the competencies to be refined, which increases the likelihood of even more acquisitions. Therefore, they conclude that the greater the number of prior M\&As the higher the probability of another M\&A. Trautwein (1990) also argues that firms systematically fall back upon these routines that have been successful in the past. As a result, firms with prior experience with M\&Aactivities will make further use of M\&As. A similar argument has been developed for SAs. Pisano (1989), Gulati (1995a) and Powell et al. (1996) argue that partners have the opportunity to learn about each other during alliances. Collaboration is a learning process and firms develop capabilities or interfirm routines for interacting with each other over time. Partners become acquainted with each other's idiosyncrasies, thereby deepening their mutual understanding, which in turn improves the quality of the relationship. Parkhe (1993) and Gulati $(1995 \mathrm{a} ; 1995 \mathrm{~b})$ relate prior alliances to trust breeding. Prior alliances provide information about the partnering firm so that the hazards associated with new SAs can be reduced. Two firms with prior SA links are likely to trust each other more than other firms with whom they have had no alliances (Ring and Van de Ven (1989)), so that the probability of future SAs is larger for firms with prior alliances.

Hypothesis 3a:

The greater the number of prior SAs between two firms, the larger the probability that further interactions between them will have the form of SAs and not M\&As. 
Different authors have mentioned the possibility that firms may use an incremental strategy when it comes to the external acquisition of technology: First they establish an alliance with another firm and subsequently they acquire their partner. This behavior can be explained in the following way. The value of the technology or intangible assets of another firm is in many cases hard to evaluate. Companies may prefer to team up first with another firm in order to learn about about the real value of its technology or intangible assets at a small investment cost before they acquire it (Doz, Hamel and Prahalad (1986); Kogut (1991); Bowman and Hurry (1993)). These arguments in favor of incremental strategies implicitly assume that, in external technology sourcing strategies, full control is preferable above collaboration with other partners (Kay (1991)); Strategic alliances are only an intermediate step alleviating the inconveniences of acquisitions. Hence, the occurence of alliances may be a good indication that future M\&As will follow. As a result, we suggest in a similar way as Hagedoorn and Sadowski (1996) that:

Hypothesis $3 b$ :

The greater the number of prior SAs between two firms, the larger the probability that further interactions between them will have the form of M\&As and not SAs.

So far, little empirical research has been performed concerning the impact of prior alliances on M\&A-activities. There are two notable exceptions to our knowledge. Kogut's (1988a) study about joint ventures shows that $25 \%$ of the joint ventures were acquired by either partner during the following years. Hagedoorn and Sadowski (1996) found that only $2.6 \%$ from a total of 6425 strategic technology alliances were transformed into M\&As. They conclude that prior strategic technology partnering plays hardly any direct role when companies form M\&As.

\section{4}

The impact of indirect linkages in the prior SA-network

Two firms can also be linked indirectly by a common partner or by a set of common partners interconnected by a chain of SAs. Even in absence of direct ties, being close in the prior SAnetwork provides firms with information about each other through indirect experiences. Furthermore, common ties or being close in the prior SA-network can encourage reputational effects and enforceable trust (Raub and Weesie (1990); Gulati (1995a)). As a result, indirect connections mobilize firms to form new SAs with each other as they are better informed about 
the potential partners (technological) capabilities and when they have a reputation of being trustworthy. We only take into consideration the shortest possible path between two firms in the SA-network because of the diminishing value of indirect referrals.

Hypothesis 4: $\quad$ The shorter the shortest path between two companies in the prior SA-network the more likely they will form new alliances and the smaller the chance that they will be jointly involved in $M \& A$ activities.

So far, we have assessed the impact of several dyad characteristics on the choice between SAs and M\&As. Characteristics of the two partnering firms in the dyad are also likely to influence that decision. Firms that have entered numerous SAs in the past are most probably those firms that were seeking vigorously for access to new technology. Through experience at collaborating, firms are better able to position themselves in information-rich positions (Powell et al. (1996)), which, in turn, is a basic condition to get access to and exploit leading edge technology. Hence, more experienced firms - i.e., those that are centrally located in the SA-network in terms of the number of prior alliances - are more likely to get timely access to new technologies that are necessary to create a competitive advantage. As a consequence, a firm that can move into a central position within the prior SA-network, decreases the probability that it will be acquired. A strong technological position leads also to increased growth potential, enhancing the firm's chance of becoming an acquirer.

Network centrality can not only be measured in terms of the number of prior alliances, i.e. the SA-experience of a firm, but also in terms of its independence from the control of others for access to information and in terms of control over other firms that are only indirectly linked to each other. Both concepts are proxies for the prominence of firms in a network.

Hypothesis 5: $\quad$ More (a) experienced and more (b) prominent firms in the prior SA-network are less likely to be acquired and are more likely to become acquirers. 
The choice between SAs and M\&As can also be influenced by other factors than dyad and firm characteristics. At the national and industry level SAs as well as M\&As come in waves. One possible explanation for this phenomenon is that SAs may become fashionable, in which an initial (set of) SAs create(s) a bandwagon effect. The same reasoning applies to M\&As (Hay and Morris (1991); Van Wegberg (1994b)). An alternative explanation of the occurrence of waves is that several changes in the environment may be responsible for the SA- and M\&Awaves (Amburgey and Miner (1992); Stigler (1950)).

Hypothesis 6: $\quad$ As SAs and M\&As come in waves which extend over several years, the relative frequency of SAs (or $M \& A s$ ) should be positively related to that of the previous year.

The ASIC-industry is a relatively young high-tech industry that evolved slowly towards maturity in the period 1980-1995. As the industry is maturing, it is reasonable to assume that SAs and M\&As play a different role nowadays than a decade ago. Harrigan (1985, 1986, 1988) pointed out that there is a relationship between industry evolution and the incidence of cooperative agreements and M\&As. She argues that cooperative agreements are transitional strategies, and that the period in which they are most appropriate is short. In young industries, technology is still in a fluid state, entailing a large amount of uncertainty. Firms, then are often engage in short-lived technology based cooperative agreements to keep abreast of the quickly changing technology by means of relatively small investments. As an industry becomes more mature the rate of technological change slows down and technological uncertainty diminishes, so that the relative importance of technology based Sas declines. At the same time, opportunities for internal growth shrink as the industry growth rate slows down. In order to consolidate their sales firm may choose for expansion strategies through M\&As.

Hypothesis 7: $\quad$ There will be an increasing preference for M\&As over SAs over time when the industry is evolving towards increasing maturity.

\section{Method}

We examined the factors that affect the companies' choice between strategic technology 
alliances or mergers and acquisitions. For the purpose of the present analysis we used a dyad as a unit of analysis. SAs and M\&As were collected in which at least one ASIC-producer was involved during the period 1985-1994, a period that was characterized by strong industry turbulence due to the establishment of numerous SAs and M\&As. This cross-sectional timeseries panel enabled us to assess the influence of several factors on the choice between SAs and M\&As.

\subsection{Data}

The sample includes 140 M\&As and 137 SAs which were established in the period 1985-1994. These agreements between firms were entered as dyads. SAs were considered to be nondirectional so that reversed ordered dyads were not included. M\&As are, of course, directional: there is the acquirer and the acquired firm. As a result, the data structure is a crosssectional time-series panel, in which each dyad includes the dependent variable, indicating if the dyad is a M\&A or a SA, and time-varying and time-constant covariates characterizing the dyad.

In order to find out to what extent prior strategic technology alliances influence the choice between newly established strategic alliances or mergers and acquisitions, we combined data from two sources. The first one is the MERIT-CATI data bank on strategic technology alliances (Duysters (1993)) ${ }^{6}$. The second one is the Securities Data data set in M\&As. A selection was made of SAs and M\&As whose major focus was on (technological developments in) the ASIC-industry. The CATI-MERIT data bank covers the period between 1975 and 1994: For that period 214 strategic technology alliances were detected. The Securities Data data set listed 140 M\&As for the period 1985-1994. M\&As which were announced before 1984 were not available. There were 137 SAs established in the period 1985-1994. As a result, there is almost an equal distribution between SAs (49.5\%) and M\&As (50.5\%) for that period.

There were 52 acquirers and 120 firms that were acquired. Since the paper is working on the mother company level, company names can be mentioned both as acquired firm and acquirer; 17 firms acquired and divested ASIC related business in the period 1985-1994.

6 Strategic technology alliances include joint research projects, joint development agreements, cross licensing, (mutual) second source agreements, technology sharing, R\&D consortia, minority holdings and joint ventures, but no licensing agreements or production and marketing agreements. 
There were 118 different firms involved in the SAs. A considerable number of firms were active in both SAs and M\&As; 31 (59.6\%) acquirers were also establishing one or more SAs in 1985-1994 and 28 (23.3\%) acquired firms were involved in prior SAs. The distribution between SAs and M\&As varies considerably over time. The following figure gives evidence of the fact that SAs and M\&As tend to come in waves. The literature provides different theoretical explanations for this phenomenon: The occurrence of merger waves has been explained by institutional changes (Stigler (1950), business cycles (Town (1992); Van Wegberg (1994a)), or by a bandwagon effect (Hay and Morrison (1991)).

\section{Insert here figure 3}

A sharp increase in SAs occurred in de early and mid-eighties. Their popularity diminished in the late eighties and the early nineties. During that period M\&As became relatively more important. The SAs are mainly non-equity agreements (77.1\%) of which the majority are joint development agreements (51.9\% of all SAs). Joint ventures are the most important form of equity SAs. The evolution of equity and non-equity SAs is presented in the following figure.

\section{Insert here figure 4}

Left-censoring is a frequently occurring problem in longitudinal analysis, because most of the sample firms existed before the start of the observation period in 1985. As data were available for SAs back to 1975 but not for M\&As, we circumvented the left-censoring problem by restricting our attention to the possible impact of prior SAs on the choice between SAs and M\&As. The possible impact of a firm's history in acquiring other firms is an issue that cannot be analysed here.

We modeled the choice between SAs and M\&As using the following random effect probit model: 


$$
\begin{aligned}
& y_{i j t}=\Phi\left(a+b \cdot x_{i j}+c \cdot x_{i j t}+\alpha_{i j}+u_{i j t}\right) \\
& \text { with } \quad E \alpha_{i j}=E u_{i j t}=0 \\
& \operatorname{Var}\left(v_{i j t}\right)=\sigma_{u}^{2}+\sigma_{\alpha}^{2}
\end{aligned}
$$

Where $y_{\mathrm{ijt}}$ is the probability at time $\mathrm{t}$ that the announcement of external technology acquisition between firms $i$ and $j$ takes the form of an $\mathrm{SA}$; $\mathrm{x}_{\mathrm{ij}}$ is a time-constant vector of explanatory variables or covariates characterizing the dyad between firms $i$ and $j$; $x_{i j t}$ is a time-varying vector of explanatory variables or covariates characterizing the dyad between firms $i$ and $j$. The error term $\mathrm{v}_{\mathrm{ijt}}$ is decomposed into two terms: ${ }_{\mathrm{ij}}$ reflects the unobserved time-constant effects which are not captured by the independent effects and $\mathrm{u}_{\mathrm{ijt}}$ is the usual error term which is independently distributed over de dyads ij, with arbitrary serial correlation. Finally, $\Phi$ is the cumulative normal distribution function. The model account for unobserved heterogeneity using a random-effects approach (Butler and Moffitt (1982)). This random-effects technique is computed by means of a routine available in LIMDEP 7.0 (Greene (1996)).

\section{3}

\section{Variables}

The dependent variable is a binary choice variable, indicating whether the pair of firms entered a SA or a M\&A. A SA was coded 1 and a M\&A 0 . No dyad appeared twice in a given year. Each dyad record includes a number of characteristics of the external action, of both firms, and of the industry as a whole. Different aspects of prior cumulative alliance activities until a given year are also included as explanatory variables.

\subsubsection{Explanatory variables}

Following the research method of Gulati (1995a), we computed a few social structural measures by constructing adjacency matrices representing the relationships between the firms in a SA-network. We computed matrices including all alliance activity among the panel members prior to a given year. Various network measures were calculated using UCINET IV (Borgatti, Everett and Freeman (1992)). In constructing particular network measures of past alliances, a few choices have been made how to treat alliances. First, we did not take into account the different types of alliances. Alliances vary from equity joint ventures and minority holdings with a strong organizational commitment and interdependence between allies to non-equity 
joint ventures which imply only moderate levels of organizational commitment although stronger than arm's length licensing agreements. There some authors weight each type of SA according to the strength of their relationship ${ }^{7}$. Second, we just added the number of ties between two firms over the observed time period. Gulati (1995a) mentions two alternatives adding the number of ties and normalizing them by the maximum score possible in that year on the one hand and the use of a Gutman scale on the other hand - but we are not making use of them for this study. The third choice relates to the length of the period during which prior SAs are likely to have an influence on the current choice between SAs and M\&As. One can include all past alliances into the calculation of the social network variables, assuming that all prior ties, no matter how long they have been established, have an impact on current firm behavior. Given the short period of observation, this could be a reasonable assumption. However, we chose for a moving window approach, assuming that only ongoing alliances have an impact on the choice between SAs and M\&As. We have an indication about the termination of the alliance for $62(29.0 \%)$ SAs in the sample. For these SAs we assumed that they have an impact on the current choice between SAs and M\&As as long as they were not terminated. For the other SAs we assume the lifespan of alliances is usually no more than five years (Kogut (1988b; 1989)).

The following social network variables were computed in UCINET IV for each dyad for each year on the basis of the cumulative prior SAs between two companies. The first variable, called prior ties (PT), is the number of prior SAs on which both firms agreed upon. The second variable is called distance (LDIST). It stands for the shortest path between two firms in the network of prior SAs (Wasserman and Faust (1994)). The shortest path is calculated using the distance routine in UCINET IV. We took the natural logarithm of this measure for two reasons. First, a change in distance between two firms matters more when this distance is small compared to the case were this distance is already large. Second, a logarithm mitigates the effect of the distance value ${ }^{8}$ for firms that are not indirectly linked to each other by means of a path of SAs.

Other characteristics of the dyads were also included as explanatory variables. We included a dummy variable (CRB) to indicate whether SAs or M\&As took place between two firms

See Contractor and Lorange (1988); Nohria and Garcia-Pont (1991); Gulati (1995a). UCINET IV sets the distance between firms, which are not linked to one another by at least one path of any distance - i.e. disconnected subgroups - , equal to the number of firms in the network. 
from the same economic block (intra-triad) or from different blocks (inter-triad). In the same way, we used two dummy variables to make a distinction between external appropriation of technology from firms in the same industry and from those in other industries. The default is a SA or a M\&A between an ASIC-producer and a firm which is no ASIC-producer. ASICD is a first dummy variable indicating that allies or acquirer and acquired firm are both ASIC-producers of which the (major) ASIC-sales come from a different submarket, e.g. a gate array producer and a PLD producer. ASICS is another dummy variable indicating that both firms realise (the largest share of) their ASIC-sales in the same submarkets, e.g. two PLD-producers.

Besides dyad characteristics we also included firm characteristics as explanatory variables. We focus on two variables which are related to the prior cumulative SA-experience of each partnering firm in the dyad. The first variable is the number of past SAs entered by each firm in the dyad prior to the given year. This variable is called the SA-history (H1 and H2) of both partnering firms in the dyad. The second variable is centrality. This variable measures how well connected, or active, a firm is in the overall network of past alliances. Centrality can be operationalized in different ways. Degree centrality (C1D and C2D) measures the centrality of a firm in terms of the number of other firms to which it is connected to, ignoring how well those partners are connected. Closeness centrality $(\mathrm{C} 1 \mathrm{C}$ and $\mathrm{C} 2 \mathrm{C})$ measures how close a firm is to all other firms in the network of prior SAs. Firms with central locations with respect to closeness have access to many other companies and do not rely on specific other firms for access to information. However, closeness centrality is not suited for the purpose of this study, since this centrality measure is only meaningful for connected graphs ${ }^{9}$. A third centrality measure is the betweenness centrality $(\mathrm{C} 1 \mathrm{~B}$ and $\mathrm{C} 2 \mathrm{~B})$ and it measures the potential control of a firm over other firms that have no direct tie between each other. We used normalized centrality measures, controlling for the overall network size, in order to make centrality measures of a firm comparable across different years.

The inclusion SA-history of firms and the centrality measures controls for firm-level heterogeneity (Heckman and Borjas (1980)). However, these variables are highly correlated. To deal with the problems of collinearity we only included the betweenness centrality measure for both firms as explanatory variables. Finally, we included two variables that reflect industry characte-

\footnotetext{
$9 \quad$ See Wasserman and Faust (1994, p.185).
} 
ristics. The first one is the annual \% growth of the ASIC market (GROW), reflecting the bias in favour of SAs in the early and dynamic stages of the industry (technology) cycle. The second one is the share of SAs (SHSA) in the previous year. This variable allows us to assess the claims that the choice between SAs and M\&As may be the result of a bandwagon effect.

\subsection{2 $\quad \underline{\text { Some control variables }}$}

We also inserted two control variables which are likely to affect the choice between SAs and M\&As but which were not included in the discussion of the hypotheses. The two variables are raw proxies for firm size. The first one is a dummy variable (TOP) indicating whether a company belongs to the top-10 ASIC-vendors in a particular year. The second one (CAPT) is another dummy variable in order to capture the effect of large companies that produce ASICs only for their internal needs (captive market) but who are at the same time important companies in terms of technological capabilities. Controlling for size is necessary since several authors have examined the particular role that large firms play in forming SAs and in the acquisition activities ${ }^{10}$. Foray (1991) and Hagedoorn and Duysters (1996) argue that large firms have a high degree of strategic freedom allowing them to pursue a strategy that leads to a mix of integration and cooperation. Smaller firms do not have this freedom to choose their strategy so that the way how small and large firms acquire new technological capabilities may differ significantly.

\section{Results}

The estimated parameters are reported in the following table. The third column, reporting the random-effects model, generates a parameter rho, which is an indicator of the presence or absence of heterogeneity. The estimate is not significant and close to zero indicating that all the time dependence in the choice between SAs and M\&As can be ascribed to the independent variables in the model. If there is no discernible evidence of random effects - i.e. when the estimate of rho turns out to be negligible - LIMDEP reports the results for the basic probit model.

Insert here about table 3

10 For SAs see Ghemawat, Porter and Rawlinson (1986) and Mytelka (1991). For M\&As see Haspeslagh and Jemison (1991) and Hoskisson and Hitt (1994). 
Several conclusions can be drawn from the results in table 3. The existence of prior alliances between two partners increases the chances that one acquires the other. This finding supports the existence of incremental strategies in which firms use alliances as vehicles for acquisition or divesture (hypothesis $3 b$ ). The results do not support the routine behaviour argument (hypothesis 3a). However, indirect ties in the prior SA-network increase the likelihood that two firms establish a SA (hypothesis 4). Consequently, we can conclude that indirect ties in a prior SA-network serves as a basis for reputational effects which mobilize firms to new SAs, while prior direct ties increases the probability of subsequent acquisition or divesture strategies.

The position in the prior SA-network of the two firms in a dyad seems also to be an important explanatory variable. Here, we only included the betweenness centrality of the two firms. The positive and significant coefficient of CB1 indicates that firms which were centrally located in the prior SA-network are less likely to become acquired by other firms. Similarly, the negative and significant coefficient of CB2 indicates that firms with a prominent role in the prior SA-network are more likely to become acquirers. Similar results were obtained when betweenness centrality was replaced by other measures of centrality or by the alliance history of the firms. These results support hypothesis 5. These variables also control for firm-level heterogeneity, which can occur if individual companies display time-constant propensities to engage in SAs or M\&As that are not captured by any of the explanatory variables.

The dummy variable CRB has a positive and significant coefficient. This means that external sourcing of technology in the ASIC-industry takes the form of M\&As in the case of intratriad dyads and SAs in the case of inter-triad dyads, as was predicted by hypothesis 1 . The other two dummy variables, ASICD and ASICS, have both positive coefficients but only that of ASICD is statistically significant. Relying on hypothesis 2, we expect negative signs for these coefficients, because M\&As are thought to occur more frequently when the industry of both partners is the same or is confined to different submarkets within the ASIC-industry. The findings do not corroborate this hypothesis, which suggests that SAs and M\&As between ASIC-producers and firms from outside the industry have a different rationale than the external technology sourcing strategies between firms within the ASIC-industry.

There is also support for the existence of waves of SAs and M\&As. The positive and significant coefficient of the SHSA-variable indicates that, once SAs or M\&As become fashionable, other firms also get involved in the same mode of external technology sourcing. Finally, 
there is strong support for hypothesis 7: As the ASIC-industry matures, firms switch from SAs to M\&As. Finally, size seems to have no impact on the choice between SAs and M\&As: The variables TOP and CAPT have insignificant coefficients. Since both variables are only raw proxies of firm size we cannot exclude that more representative proxies could give us a different picture.

\section{Conclusion and suggestions for further research}

There exists broad economic and managerial strands of literature about SAs and M\&As, but they tell us virtually nothing about the strategic choice of firms between technology based SAs and M\&As. This study provides a bridge between the two strands of literature. It examines the circumstances in which firms have a preference for SAs or M\&As as a mode for external technology sourcing.

By focussing on the dyad as the unit of analysis, this study provides empirical support for the effect of prior direct and indirect ties on the current choice between SAs and M\&As. Prior alliances between two companies increase the probability that one will acquire the other. On the contrary, indirect ties in the prior SA-network increase the probability that the two firms will form a SA. There are also relatively more M\&As between firms from the same economic block (intra-triad). SAs are preferred between firms located in different economic blocks in the triad because of the higher risk they have to bear.

The positions in the prior SA-network of the two companies in a dyad also influence the choice between SAs and M\&As. Firms that have positioned themselves in the center of that network have timely and flexible access to new technologies. This, in turn diminishes the probability of a potential acquisition and it increases the chance that the firm becomes an acquirer itself. Furthermore, the preference of the companies for SAs and M\&As is not homogeneous over the industry cycle : In the early stages they prefer SAs switching towards M\&As as the industry becomes more mature. Finally, we also found support for the mimetic behaviour of firms leading to SA- and M\&A-waves.

Although these results are promising, the study is limited in its scope. There are two major limitations to this study. First, it focuses on the ASIC-industry and further studies are needed in order to generalize these findings. Second, we did not make a distinction between equity and non-equity alliances. Differentiating between these two types of alliances may result in an 
even more accurate picture.

There are a number of fruitful directions for future research. First, the study could be enriched by including financial data for each firm mentioned. In a dyadic context, we can measure how differences between the two firms have an impact on their choice between SAs and M\&As. Second, in this study we compared only SAs and M\&As and we excluded implicitly the non-occurrence of SAs or M\&As. Making the three options explicit requires a random effect probit model for which the dependent variable is no longer bivariate. Finally, taking the dyad as unit of analysis has also its limitations and drawbacks. In order to have a complete picture on the companies' choices between SAs and M\&As this study has to be complemented by another one taking firms as the units of analysis. In this way, one could get a better understanding of a firm's choice between SAs and M\&As by relating it to its portfolio of prior external technology sourcing activities and other firm characteristics.

\section{References}

Aiken, M. and J. Hage (1968); "Organizational interdependence and intraorganizational structure”, American Sociological Review, Vol 33, pp. 912-930.

Amburgey, T. and A. Miner (1992); "Strategic Momentum: The effects of repetitive, positional, and contextual momentum on merger activity”, Strategic Management Journal, Vol. 13, pp. $335-348$.

Amburgey, T., D. Kelly and W. Barnett (1993); "Resetting the clock: The dynamics of organizational change and failure", Administrative Science Quarterly, 38, pp.51-73.

Barley, S., J. Freeman and R. Hybels (1992); "Strategic alliances in commercial biotechnology" In N. Nohria and R. Eccles (eds.), Networks and organizations: Structure, form and action, Boston: Harvard Business School Press, pp. 311-347.

Borgatti, S., M. Everett and L. Freeman (1992); UCINET IV Version 1.63, Columbia, SC: Analytic Technologies.

Bowman, E. and D. Hurry (1993); "Strategy through the option lens: An integrated view of resource investments and the incremental-choice process", Academy of Management Review, Vol. 18, pp. 760-782.

Butler, J. and R. Moffitt (1982); A computationally efficient quadrature procedure for the one factor multinomial probit model", Econometrica, 50, pp. 761-764.

Chi, T. (1994); “Trading in strategic resources: necessary conditions, transaction cost problems, and choice of exchange structure, Strategic Management Journal, Vol. 7, pp. 119-139. 
Cohen, W. and D. Levinthal (1989); "Innovation and learning", Innovation and learning: The two faces of learning”, Economic Journal, 99, 569-596.

Cohen, W. and D. Levinthal (1990); “Absorptive capacity: A new perspective on learning and innovation”, Administrative Science Quarterly, 35: pp. 128-152.

Contractor, F. and P. Lorange (eds.) (1988); Cooperative strategies in international business, Lexington (MA): Lexington Books.

Cyert, R. and J. March (1963); A behavioral theory of the firm, Prentice-Hall, Englewood Cliffs, NJ.

Doz, Y., G. Hamel and C. Prahalad (1986); Strategic partnerships: Success or surrender?, University of Michigan Working Paper.

Duysters, G. and J. Hagedoorn (1993); The cooperative agreements and technology indicators (CATI) information system, MERIT: Maastricht, $19 \mathrm{p}$.

Foray, D. (1991); The secrets of industry are in the air: Industrial cooperation and the organizational dynamics of the innovative firm, Research Policy, 20, pp. 393-405.

Ghemawat, P., M. Porter, and R. Rawlinson (1986); Patterns of international coalition activity, in M. Porter (ed.), Competition in global industries, Boston (MA), Harvard Business School Press.

Gomes-Casseres, B. (1996); The alliance revolution: The new shape of business rivalry, Cambridge (MA): Harvard University Press, 305 p.

Green, W. (1996); LIMDEP Version 7.0 User's Manual, Econometric Software.

Gulati, R. (1995a); "Social structure and alliance formation patterns: a longitudinal analysis", Administrative Science Quarterly, Vol 40, pp. 619-652.

Gulati, R. (1995b); "Does familiarity breed trust? The implications of repeated ties for contractual choice in alliances", Academy of Management Journal, Vol. 38, No. 1, pp. 85-112.

Hagedoorn, J. and G. Duysters (1996); External appropriation of innovative capabilities: The choice between strategic partnering and mergers and acquisitions, MERIT working paper, 2/96-021, 36 p.

Hagedoorn, J. And B. Sadowski (1996); Exploring the potential transition from strategic technology partnering to mergers and acquisitions, MERIT working paper 2/96-010, $33 \mathrm{p}$.

Hamel, G. (1991); "Competition for competence and inter-partner learning within international strategic alliances", Strategic Management Journal, Vol. 12, pp. 83-103.

Hannan, M. and J. Freeman (1984); "Structural inertia and organizational change", American 
Sociological Review, 49, pp. 149-164.

Harrigan, K. (1985); Strategies for joint ventures, Lexington, Mass.: D.C. Lexington Books.

Harrigan, K. (1986); Managing for joint venture success, Lexington, Mass.: D.C. Lexington Books.

Harrigan, K. (1988); "Joint ventures and competitive strategy", Strategic Management Journal, Vol. 9, pp. 141-158.

Harrigan, K. and W. Newman (1990); "Basis of interorganization co-operation: Propensity power and persistence", Journal of Management Studies, Vol 27 (4), July, pp. 417-434.

Haspeslagh, P. and D. Jemison (1991); Managing acquisitions; Creating value through corporate renewal, New York, Free Press, 416 p.

Hay, D. And D. Morris (1991); Industrial economics and organization, Oxford: Oxford University Press.

Heckman, J. and G. Borjas (1980); "Does unemployment cause future unemployment: Definitions, questions, and answers from a continuous time model of heterogeneity and state dependence", Economica, 47, pp. 247-283.

Hitt, M., R. Hoskisson, R. Ireland, and J. Harrison (1991); "Effects of acquisitions on R\&D inputs and outputs", Academy of Management Journal, Vol. 34 (3), pp. 693-706.

Hoskisson, R. and M. Hitt (1994); Downscoping - how to tame the diversified firm, Oxford, Oxford University Press.

Hurry, D. (1993); "Restructuring in the global economy; the consequences of strategic linkages between Japanese and U.S. firms", Strategic Management Journal, Vol 14, pp. 69-82.

Kay , N. (1991); "Industrial collaborative activity and completion of the internal market", Journal of common market studies, Vol. 29, No. 4 June, pp. 347-362.

Kogut, B. (1988a); "Joint ventures: Theoretical and empirical perspectives", Strategic Management Journal, Vol 9, pp. 319-332.

Kogut, B. (1988b); "A study of the life cycle of joint ventures". In : F. Contractor and P. Lorange (eds.), Cooperative strategies in international business, Lexington, MA: Lexington Books, pp. 169-186.

Kogut, B. (1989); "The stability of joint ventures: Reciprocity and competitive rivalry", Journal of Industrial Economics, Vol 38, pp. 183-198.

Kogut, B. (1991); "Joint ventures and the option to expand and acquire", Management science, Vol. 37, pp. 19-33. 
Leonard-Barton, D. (1994); The wellsprings of knowledge, Boston: Harvard Business School Press, $334 \mathrm{p}$.

Mueller, D. (1989); "Mergers; Causes, effects and policies", International Journal of Industrial Organization, Vol 7 (1), pp. 315-347.

Mytelka, L. (ed.) (1991); Strategic partnerships and the world economy, London, Pinter.

Nelson, R. and S. Winter (1982); The evolutionary theory of economic change, Harvard University Press, Cambridge, MA.

Nohria, N. and C. Garcia-Pont (1991); "Global strategic linkages and industry structure", Strategic Management Journal, Vol. 12, pp. 105-124.

Parkhe, A. (1993); "Strategic alliance structuring: A game theoretic and transaction cost examination of interfirm cooperation", Academy of Management Journal, Vol. 36, No. 4, pp. 794829.

Perry, M. and R. Porter (1985); "Oligopoly and the incentive for horizontal merger", American Economic Review, March, Vol 75 (1), pp. 219-227.

Pisano, G. (1989); "Using equity participation to support exchange: Evidence from the biotechnology industry", Journal of Law, Economics, and Organization, Vol. 5, Nr. 1, pp. 109-126.

Porter, M. and M. Fuller (1986); "Coalitions and global strategy", In M. Porter (ed.), Competition in global industries, Poston : Harvard Business School Press, pp. 315-344.

Powell, W. and P. Brantley (1992); Competitive cooperation in biotechnology: Learning through networks? (Chapter 14), In. N. Nohria and R. Eccles (eds.), Networks and organisations : Structure, form and action, Boston : Harvard Business School Press, pp. 366-394.

Powell, W., K. Koput and L. Smitt-Doerr (1996); "Interorganizational collaboration and the locus of innovation: Networks of learning in biotechnology", Administrative Science Quarterly, Vol. 41, 116-145.

Raub, W. and J. Weesie (1990); "Reputation and efficiency in social interactions: An example of network effects", American Journal of Sociology, 96, pp. 626-654.

Ring, P. and Van de Ven (1992); "Structuring cooperative relationships between organizations", Strategic Management Journal, Vol. 13, pp. 483-498.

Roberts, E. and C. Berry (1985); "Entering new business: selecting strategies for succes", Sloan Management Review, Vol. 26, pp. 3-17.

Stigler, G. (1950); "Monopoly and oligopoly by merger", American Economic Review Proceedings, May, Vol. 40, pp. 51-70. 
Teece, D. (1986); "Profiting from technological innovation", Research Policy, Vol 15, pp. 286305.

Teece, D. (1992); "Competition, cooperation and innovation : Organizational arrangements for regimes of rapid technological progress", Journal for Economic Behavior and Organization, Vol. 18, pp. 1-25.

Town, R. (1992); "Merger waves and the structure of merger and acquisitions time-series", Journal of Applied Econometrics, Vol.7, pp. 83-100.

Trautwein, F. (1990); "Merger motives and merger prescriptions", Strategic Management Journal, Vol 11, pp. 283-295.

Van Wegberg, M. (1994a); Why do mergers occur in waves? Business cycles, bandwagons and the merger for market power paradox, METEOR: Maastricht, Research Memorandum/0/94-022, $17 \mathrm{p}$.

Van Wegberg, M. (1994b); Merger waves, their historical and structural causes: A survey of views in industrial economics, METEOR: Maastricht, Research Memorandum/0/94-024, 27 p.

Wasserman, S. And K. Faust (1994); Social network analysis: methods and applications, Cambridge: Cambridge University Press, 825 p. 
Table 2: Community aversion ratio for different level of market completion

\begin{tabular}{|c|c|c|c|c|c|}
\hline $\begin{array}{l}\text { Degree of market } \\
\text { completion }\end{array}$ & Domain & $\begin{array}{l}\text { Industry } \\
83-88\end{array}$ & $\begin{array}{r}\text { High-tech industry* } \\
83-88\end{array}$ & & \\
\hline High & & National & 4.5 & & 2.9 \\
\hline Medium & Communi & 3.3 & & 1.7 & \\
\hline Low & & International & 1.0 & & \\
\hline
\end{tabular}

Source:

Kay (1991, p. 356 and p. 361).

Excluding chemicals 
Table 3 : Probit and random-effects probit estimates

\begin{tabular}{|l|c|}
\hline \multicolumn{1}{|c|}{ Variable } & $\begin{array}{c}\text { Random-ef- } \\
\text { fects } \\
\text { probit }\end{array}$ \\
\hline Constant & $-1.376^{* * *}$ \\
& $(-2.735)$ \\
LDIST & $-0.206^{* *}$ \\
& $(-2.075)$ \\
PT & $-1.058^{* *}$ \\
& $(-2.075)$ \\
CRB & $0.607^{* *}$ \\
& $(2.508)$ \\
ASICD & $0.975^{* * *}$ \\
& $(3.355)$ \\
ASICS & 0.131 \\
& $(0.522)$ \\
C1B & $0.079^{* *}$ \\
& $(2.129)$ \\
C2B & $-0.044^{*}$ \\
CAPT & $(-1.779)$ \\
& -0.309 \\
TOP & $(-0.926)$ \\
& 0.181 \\
GROW & $(0.779)$ \\
SHSA & $0.037^{* *}$ \\
Rho & $(2.371)$ \\
& $0.013^{* *}$ \\
N & $(2.423)$ \\
Log -L & 0.043 \\
Chi ${ }^{2}$ & $(0.101)$ \\
Log-LRE & \\
Chi ${ }^{2}$ & 209 \\
& \\
& -127.04 \\
& 0.28 \\
& \\
\hline
\end{tabular}

Legend: $* * *>1 \%$ significance

$* * \quad 1 \%-5 \%$ significance

* $\quad 5 \%-10 \%$ significance 